Proceedings of the 16th Czech and Slovak Conference on Magnetism, Košice, Slovakia, June 13-17, 2016

\title{
Accents in Modern High Saturation Nanocrystalline Fe-Rich Alloys
}

\author{
B. Butvinová ${ }^{a, *}$, P. Butvin ${ }^{a}$, I. MaŤKo ${ }^{a}$, D. JAniČKoviČ $^{a}$, M. Kuzminski $^{b}$, A. \\ Ślawska-WANiewska ${ }^{b}, \mathrm{P}$. Švec SR. ${ }^{a}$ AND M. ChromČÍKOVÁ ${ }^{c}$ \\ ${ }^{a}$ Institute of Physics, SAS, Dúbravská cesta 9, 84511 Bratislava, Slovakia \\ ${ }^{b}$ Institute of Physics, Polish Academy of Sciences, Aleja Lotnikow 32/46, PL-02668 Warsaw, Poland \\ ${ }^{c}$ Institute of Inorganic Chemistry, SAS, Centrum VILA, Študentská 2, 91150 Trenčín, Slovakia
}

Post processing limits for iron-rich $\mathrm{Fe}-\mathrm{Cu}-\mathrm{Si}-\mathrm{B}-\mathrm{P}$ high-induction rapidly-quenched ribbons have been tested. $530{ }^{\circ} \mathrm{C} / 20 \mathrm{~min}$ is already too much, formed borides being the essential culprit of magnetic properties deterioration. Unlike standard Si-poor Fe-Nb-Cu-B-Si Finemets, these alloys annealed even in "technical" Ar below the upper limit do not create significant squeezing surfaces.

DOI: 10.12693/APhysPolA.131.711

PACS/topics: 75.50.Bb, 75.60.-d, 75.75.-c

\section{Introduction}

Persistent demand for high-induction (hi-B) cheap soft-magnetic materials led some ten years ago to probing the idea to enhance induction by increasing the percentage of cheap iron and to spare "exotic/strategic" (expensive, the Curie temperature $\left(T_{\mathrm{C}}\right)$ lowering) components as $\mathrm{Nb}$ or Mo from proven $\mathrm{Fe}-\mathrm{Nb} / \mathrm{Mo}-\mathrm{Cu}-\mathrm{B}-\mathrm{Si}$ Finemets $[1,2]$. As the previous experience with Finemets showed some properties (fine crystalline grain, no excessive magnetostriction...) to be actually needed to obtain good soft-magnetic material produced by already proven and efficient RQM technology, certain changes due to changed composition to post-processing precursor ribbons had to be made: lack of the grain-growth blocker $(\mathrm{Nb}, \mathrm{Mo})$ requires the reduction of annealing temperature and duration, B and Si have to be kept for hampering "premature" uncontrolled crystallization and limiting magnetostriction despite of lowering $T_{\mathrm{C}}$ [3]. Other metalloids $(\mathrm{P}, \mathrm{C})$ are tried to help or partially substitute $\mathrm{B}$ and $\mathrm{Si}[4,5]$.

We tried to "taste" the limits of viable composition and annealing conditions to obtain such a modern useful material. We did not seek for "the best" hi-B material. We targeted the evolution of surface effects within the annealing range and looked for differences to $\mathrm{Fe}-\mathrm{Nb}-\mathrm{Cu}-\mathrm{B}-\mathrm{Si}$ Finemets [6] to better resolve the role of changed components and annealing conditions. Therefore we swept annealing temperature from the first appearance of desired crystalline bcc- $\mathrm{Fe}(\mathrm{Si})$ phase to significant deterioration of soft-magnetic properties and kept the longer duration $(20 \div 30 \mathrm{~min})$, which we consider better practicable with post processing of more massive magnetic cores in industrial scale production and providing better long-term stability.

*corresponding author; e-mail: beata.butvinova@savba.sk

\section{Materials and methods}

Ribbons of $\mathrm{Fe}-\mathrm{Cu}-\mathrm{B}-\mathrm{Si}-\mathrm{P}$ composition (see Table I) have been prepared by planar-flow casting method on air. Strips of 3 and $6 \mathrm{~mm}$ width, $15 \div 21 \mu \mathrm{m}$ thickness and $10 \mathrm{~cm}$ length were annealed in vacuum or in flowing technical Ar (furnace was not evacuated before annealing) at $420,450,480$ and $520^{\circ} \mathrm{C}$ with duration of 20,30 , and $60 \mathrm{~min}$ for testing. Hysteresis loops were recorded using a digitizing hysteresis graph at standard ac $(21 \mathrm{~Hz})$ sinusoidal $H$ excitation in the Helmholtz drive coils along the ribbon long axis. Nanocrystallization of examined samples was checked by simultaneous thermal analysis (STA) to estimate the critical temperatures and X-ray diffraction (XRD) with the $\mathrm{Cu} K_{\alpha}$ radiation. To check the composition, electron dispersive spectroscopy (EDS) was used and verification of ribbon thickness was done by electron microscopy because buoyancy method to determine the density was problematic due to small sample volume. We used TAQ400E dilatometer for mechanical tests (force ramp and sudden loading response). Magnetic domain structure has been observed by digitallyenhanced MOKE-based setup.

\section{Results and discussion}

Amorphous alloys (all observed as-cast ribbons were amorphous) were thermally analyzed with temperature rate $10^{\circ} \mathrm{C} /$ min to determine critical temperatures: crystalline onset temperature $T_{x}, T_{p}$ - peak heat-flow crystallization temperature and the Curie temperature $T_{\mathrm{C}}$ (see Table I). $T_{\mathrm{C}}$ of as-cast state rises with adding more $\mathrm{Si}\left(\mathrm{Si}_{4}\right.$ to $\left.\mathrm{Si}_{8}\right)$ from $340^{\circ} \mathrm{C}$ to $394^{\circ} \mathrm{C}$. Differential scanning calorimetry (DSC) curves show two crystallization peaks. First nanocrystallization $T_{p 1}$ runs near $400^{\circ} \mathrm{C}$ $\div 457^{\circ} \mathrm{C}$ correspond with bcc-Fe( $\mathrm{Si}$ ) phase (confirmed by $\mathrm{XRD}$ analysis) and second crystalline temperature $T_{p 2}$ is about $550^{\circ} \mathrm{C}$ for all investigated ribbons. The ribbons are usually partly nanocrystalline after low temperature 
annealing $420^{\circ} \mathrm{C} / 30$ and 60 min except of sample \#4. It is reflected by hysteresis loops which are upright after vacuum and Ar annealing except \#4 that remains slightly round after $420^{\circ} \mathrm{C}$ anneal (see Fig. 1 and Fig. 2). Whereas vacuum annealing does not result in appreciable loop tilt (apart from the highest $530^{\circ} \mathrm{C}$ ) some alloys show the tilt modest increase with annealing temperature after $\mathrm{Ar}$ annealing.

TABLE I

The investigated ribbon composition and critical temperatures $\left[{ }^{\circ} \mathrm{C}\right]$.

\begin{tabular}{c|c|c|c|c|c|c}
\hline \hline & Composition & $T_{\mathrm{C}}$ & $T_{x 1}$ & $T_{p 1}$ & $T_{x 2}$ & $T_{p 2}$ \\
\hline$\# 1$ & $\mathrm{Fe}_{82} \mathrm{Cu}_{1} \mathrm{~B}_{10} \mathrm{Si}_{4} \mathrm{P}_{3}$ & 340 & 400 & 414 & 542 & 549 \\
\hline$\# 2$ & $\mathrm{Fe}_{80} \mathrm{Cu}_{1} \mathrm{~B}_{11} \mathrm{Si}_{4} \mathrm{P}_{4}$ & 338 & 400 & 413 & 538 & 544 \\
\hline$\# 3$ & $\mathrm{Fe}_{78} \mathrm{Cu}_{1} \mathrm{~B}_{10} \mathrm{Si}_{8} \mathrm{P}_{3}$ & 372 & 420 & 435 & 548 & 554 \\
\hline$\# 4$ & $\mathrm{Fe}_{76} \mathrm{Cu}_{1} \mathrm{~B}_{11} \mathrm{Si}_{8} \mathrm{P}_{4}$ & 394 & 457 & 468 & 548 & 552
\end{tabular}

All alloys show magnetic hardening after $530{ }^{\circ} \mathrm{C}$ anneal with large coercivity and poor approach to saturation (see Fig. 1, upper part). The latter comes best for \#4 however in vacuum only.

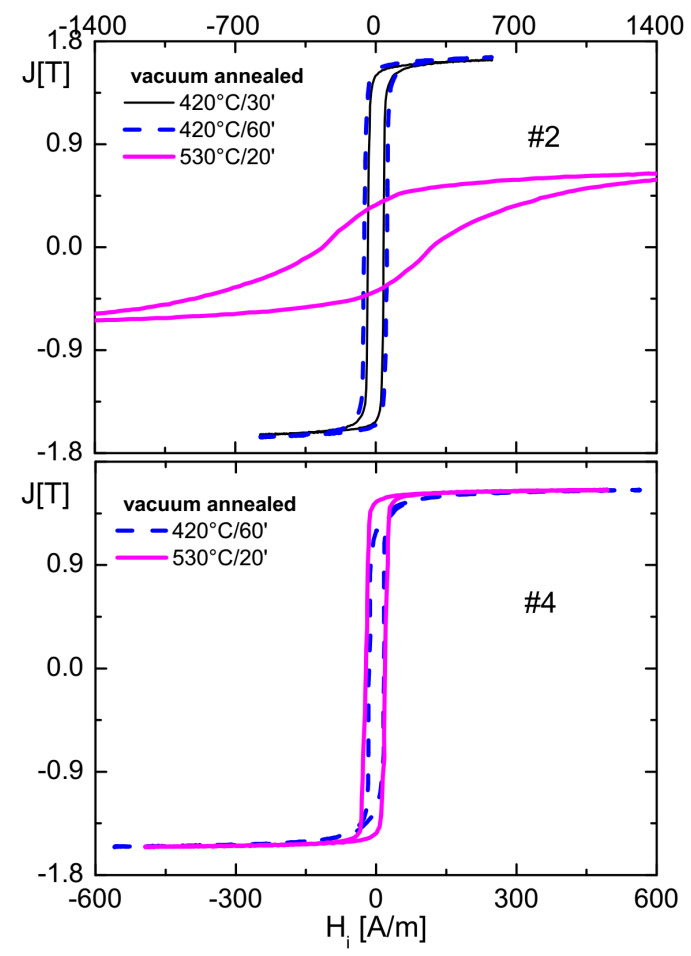

Fig. 1. Hysteresis loops of vacuum-annealed $\mathrm{Fe}_{80} \mathrm{Cu}_{1} \mathrm{~B}_{11} \mathrm{Si}_{4} \mathrm{P}_{4}$ and $\mathrm{Fe}_{76} \mathrm{Cu}_{1} \mathrm{~B}_{11} \mathrm{Si}_{8} \mathrm{P}_{4}$.

Since no appreciable creep-induced-like magnetic anisotropy (CILA) to counter or support the tilt has been detected, the increasing loop tilt means increasing surface squeeze of the underlying positively magnetostrictive ribbon interior, however much weaker than known from more annealed Si-poor Finemets [6]. Nevertheless, Ar annealing evidently promotes precipitation of borides at

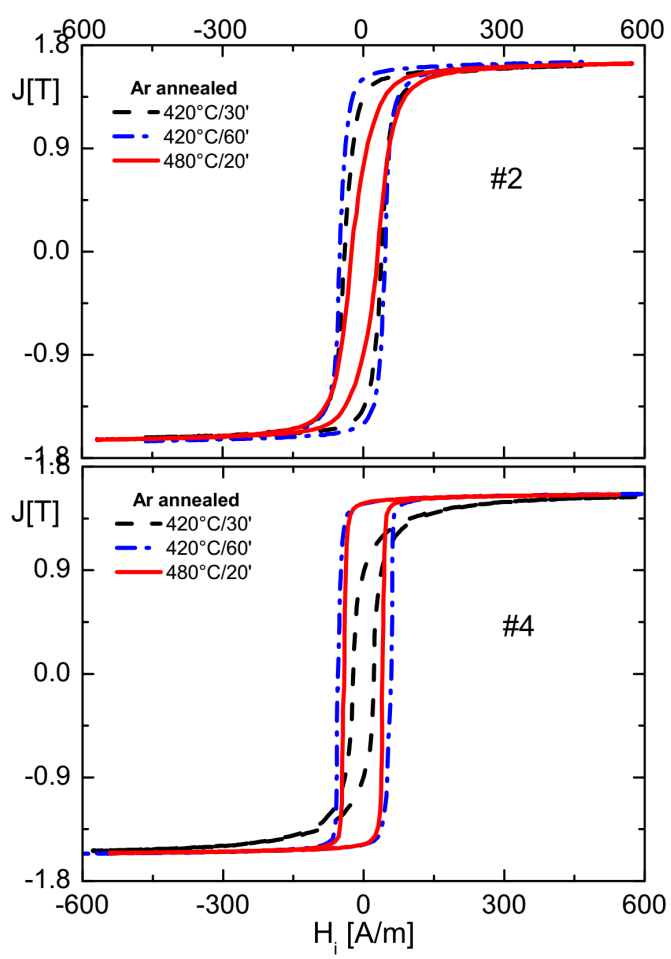

Fig. 2. Hysteresis loops of Ar-anealed $\mathrm{Fe}_{80} \mathrm{Cu}_{1} \mathrm{~B}_{11} \mathrm{Si}_{4} \mathrm{P}_{4}$ and $\mathrm{Fe}_{76} \mathrm{Cu}_{1} \mathrm{~B}_{11} \mathrm{Si}_{8} \mathrm{P}_{4}$.

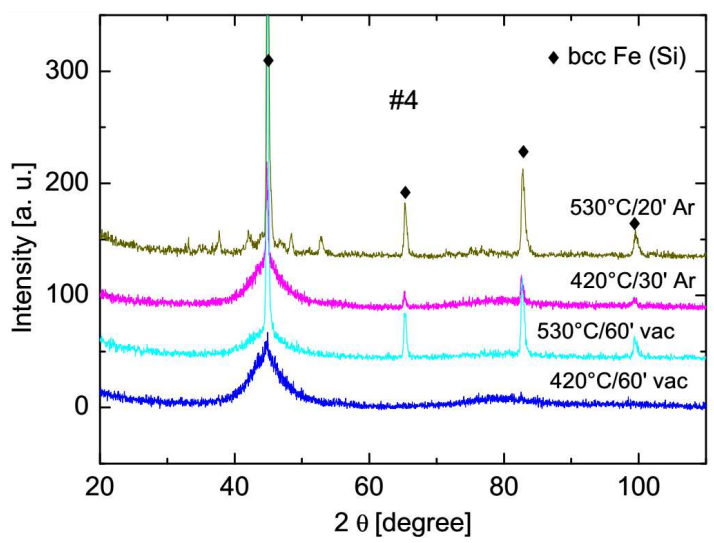

Fig. 3. XRD patterns of annealed $\mathrm{Fe}_{76} \mathrm{Cu}_{1} \mathrm{~B}_{11} \mathrm{Si}_{8} \mathrm{P}_{4}-$ $\# 4$.

higher temperatures. So far (\#1 was not inspected after $530^{\circ} \mathrm{C}$ anneal), no borides were detected by XRD after vacuum anneal. The borides seen by XRD in \#4 (Fig. 3 ) and in $\# 3$ are tetragonal phosphoborides $\mathrm{Fe}_{5} \mathrm{~B}_{2} \mathrm{P}$ whereas in $\# 2$ it is $\mathrm{Fe}_{3} \mathrm{~B}_{0.63} \mathrm{P}_{0.37}$. The lattice parameter of bcc-Fe $(\mathrm{Si})$ phase (decrease in order $\# 2, \# 4, \# 3$ ) points to $\mathrm{Si}$ content increasing with more $\mathrm{Si}$ percentage in the alloy composition. The same increase is seen in the grain size (by the Scherrer formula) in $530^{\circ} \mathrm{C}$ vacuum annealed samples whereas $\approx 26 \mathrm{~nm}$ grain was observed in $530^{\circ} \mathrm{C}$ Ar-annealed samples. We consider that the larger grains occur in surfaces of an Ar-annealed ribbon.

From the observed (as well as non-observable) domain structures (Fig. 4) it is evident that considerable inho- 

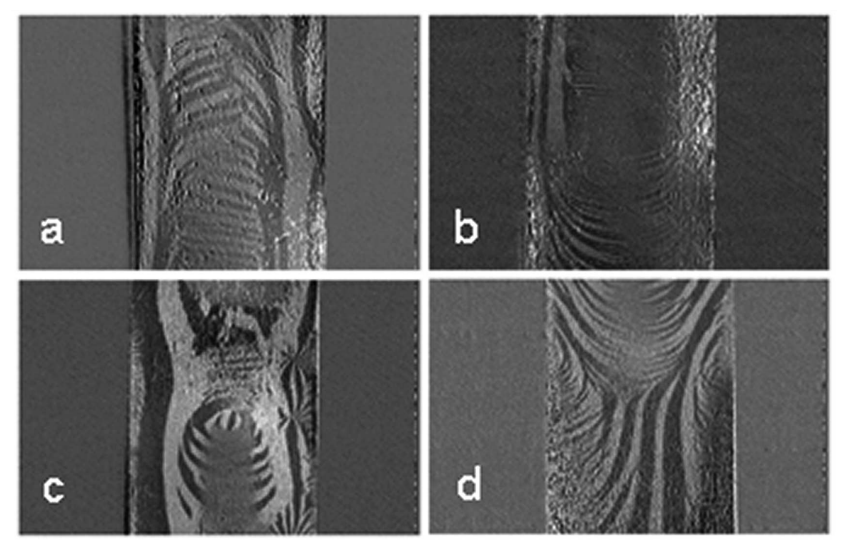

Fig. 4. Domain structures of ribbon $\# 4$ annealed: (a,c) $420^{\circ} \mathrm{C} / 60 \mathrm{~min},(\mathrm{~b}, \mathrm{~d}) 530^{\circ} \mathrm{C} / 20 \mathrm{~min}$ in vacuum. Whole ribbon width $(6 \mathrm{~mm})$ and long ribbon axis vertically is seen after demagnetization. Upper images are air sides and lower ones are wheel sides of the ribbon. Magneto-optical sensitivity is mostly vertical except (b), where it is horizontal.

mogeneous in-plane stress acts in the surfaces. Transversal tension governs the central part (transversal but not closure domains) and longitudinal tension acts along the edges more so in air-side surface. It was difficult to observe domains on Ar-annealed samples as if some non-magnetic or domain structure non-supporting substance (i.e. $\mathrm{Fe}_{2} \mathrm{O}_{3}$ ) covered the surfaces. Although no ferrous oxides have been directly identified by XRD, our experience [7] with "technical"-Ar-annealed Finemets gives this hint.

To see what happened to mechanical properties of annealed ribbons we loaded the samples with $\approx 30 \mathrm{MPa}$ longitudinal tension. We applied linear (with time) force ramp and it showed merely continuously increasing modulus after annealing in either ambience below $450^{\circ} \mathrm{C}$, whereas annealing above $450^{\circ} \mathrm{C}$ resulted in sudden onset of greater modulus at heavier loading (at $\approx 18 \mathrm{MPa}$ ). So far, there is no explanation at hand but several ones rebutted (non-planar wavy ribbon...). Then, sudden $\approx 30 \mathrm{MPa}$ loading has been applied at room temperature (RT), elongation observed during loading and after unloading to see elastic and anelastic response. We observed greater toughness (less strain at $30 \mathrm{MPa}$ and less anelasticity) of vacuum-annealed samples compared to Ar-annealed ones, which persists from $420^{\circ} \mathrm{C}$ to annealing temperatures around $520^{\circ} \mathrm{C}$ (contrary to Si-poor Fe$\mathrm{Nb}-\mathrm{Cu}-\mathrm{B}-\mathrm{Si}[8])$. To clear unexpectedly weak loop tilt after under- $500{ }^{\circ} \mathrm{C} \mathrm{Ar}$ annealing, we performed random (i.e. not each sample) tests for CILA. Annealing under 20 to $30 \mathrm{MPa}$ tensile stress at $420^{\circ} \mathrm{C}$ and $480^{\circ} \mathrm{C}$ resulted in no appreciable change (not shown) of the loop tilt due to applied stress. Thus neither magnetoelastic response to surface-generated stress at RT, nor CILA possibly formed during anneal to affect visibly the loop tilt.

\section{Conclusions}

If compared to akin but standard annealed $\mathrm{Si}$-poor $\mathrm{Fe}-$ $\mathrm{Nb}-\mathrm{Cu}-\mathrm{B}-\mathrm{Si}$ Finemets, certain significant differences appear:

- Hysteresis loops show far weaker tendency to tilt. Though the studied hi-B alloys show positive magnetostriction of the same order $\left(\approx 10^{-5}\right)$ and Ar annealing promotes development of interior-unlike surfaces, the internal stress generated appears far weaker.

- The surfaces do not generate any significant "cage effect" providing Ar-annealed samples more strainresistant. There is no appreciable CILA found after modest stress annealing below $500^{\circ} \mathrm{C}$.

The last point is most likely due mainly to shorter and lower-temperature annealing. Different composition appears to be secondary. The "limit tasting" showed that even 20 min duration of annealing could be too long and borides (phosphoborides) and even modest increase of grain size above $25 \mathrm{~nm}$ appreciably deteriorate softmagnetic properties.

\section{Acknowledgments}

This work was supported by the national grant agency VEGA under grants No. 2/0189/14, 2/0037/15 and by the Slovak Research and Development Agency (APVV) grant APVV-0460-12 and APVV-15-0621.

\section{References}

[1] A. Makino, Ch. Chang, T. Kubota, A. Inoue, J. Alloys Comp. 483, 616 (2009).

[2] Y. Yoshizawa, M. Ohta, J. Phys. Conf. Series 144, 012071 (2009).

[3] P. Sharma, X. Zhang, Y. Zhang, A. Makino, Scr. Mater. 95, 3 (2015).

[4] A. Urata, H. Matsumoto, S. Yoshida, A. Makino, J. Alloys Comp. 509S, S431 (2011).

[5] Z. Dan, K. Takenaka, Y. Zhang, S. Unami, A. Takeuchi, N. Hara, A. Makino, J. Non-Cryst. Solids 402 , 36 (2014).

[6] P. Butvin, B. Butvinová, M. Kuzminski, A. ŚlawskaWaniewska, J. Sitek, I. Matłko, M. Kadlečíková, Acta Phys. Pol. A 126, 152 (2014).

[7] B. Butvinová, P. Butvin, K. Brzózka, M. Kuzminski, I. Matkko, P. Švec Sr., M. Chromčíková, J. Magn. Magn. Mater. 424, 233 (2017).

[8] B. Butvinová, P. Butvin, P. Maťko, P. Švec Sr., M. Chromčíková, J. Sitek, J. Dekan, IEEE Trans. Magn. 50, 2002904 (2014). 